\title{
Optimal percutaneous coronary intervention strategy in a patient with non ST-segment elevation acute coronary syndrome and diffuse double vessel disease
}

\author{
Krešimir Gabaldo1*, Boris Starčević ${ }^{2}$, Đeiti Prvulović1, Božo Vujeva', Irzal Hadžibegović1 \\ 'General Hospital "Dr J. Benčević", Slavonski Brod, Croatia \\ 2University Hospital Dubrava, Zagreb, Croatia
}

Treatment of ACS patients with diffuse long lesions and multiple vessel disease in NSTE-ACS is still challenging. There are many reports which suggest that spot stenting of the narrowest segment is preferable over full lesion coverage ${ }^{1,2}$. We present a 54-year old NSTE-ACS patient with known left bundle branch block, a diffuse long lesion of proximal LCX which included LCX/OM1 bifurcation, and a highly significant stenosis of RCA. LAD was free of stenosis. The patient underwent ad hoc PCl with focal stenting of midLCX, and staged $\mathrm{PCl}$ of RCA. During routine LCX reassessment, proximal LCX dissection and plaque progression was suspected. Staged $\mathrm{PCl}$ of the LCX and OM bifurcation was done with 2 BMS and 1 DEB in the main branch, and 2 DES in the side branch. Issues of culprit lesion identification, timing and staging of total percutaneous revascularization in a multiple vessel disease in patients with NSTE-ACS are discussed. In addition, issue of focal stenting strategy versus long segment stenting in ACS is also presented and discussed.

KEYWORDS: non-ST-segment elevation acute coronary syndrome, spot stenting, bifurcation stenting, drug eluting baloon.

\section{Received: $5^{\text {th }}$ Mar 2013}

*Address for correspondence: Opća bolnica "Dr J. Benčević", Andrije Štampara 42, HR-35000 Slavonski Brod, Croatia.

Phone: +385-35-201-201

E-mail: kresimir.gabaldo@sb.t-com.hr

\section{Literature}

1. Katritsis DG, Korovesis S, Tzanalaridou E, Giazitzoglou E, Zografos T, Meier B. Spot drug-eluting stenting for long coronary stenoses: long-term results of a randomized clinical study. J Interv Cardiol. 2011;24(5):437-41.

2. Steigen TK, Maeng M, Wiseth R, Erglis A, Kumsars I, Narbute I, et al; Nordic PCI Study Group. Randomized study on simple versus complex stenting of coronary artery bifurcation lesions: the Nordic bifurcation study. Circulation. 2006;114(18):1955-61. 